\title{
Utility of Antiplatelet Therapy With Ticlopidine in Patients Refractory to Clopidogrel for Intracranial Stenting: A Single Institution Experience
}

\author{
Pratik A. Shukla a, Rahul Singh ${ }^{\mathrm{a}}$, Chirag D. Gandhi ${ }^{\mathrm{a}}$, Jacqueline Kraus ${ }^{\mathrm{a}}$, \\ Charles J. Prestigiacomo ${ }^{\mathrm{a}, \mathrm{b}}$
}

\begin{abstract}
Background: The use of antiplatelets in intra-arterial stenting for cerebrovascular disease has been associated with a decrease in morbidity and mortality. Ticlopidine, a thienopyridine that inhibits ADP-mediated platelet aggregation, has been used with aspirin to treat patients with stroke and prevent thromboembolic occlusion in patients who have undergone endovascular procedures. Because of the reported side effects associated with ticlopidine such as bleeding, thrombocytopenic thrombotic purpura and neutropenia, another thienopyridine, clopidogrel, became the agent of choice as an antiplatelet regimen. However, as the literature accumulates, it is becoming evident that many patients are resistant or allergic to clopidogrel, thus highlighting the need for an alternative antiplatelet agent to prevent complications associated with endovascular management.
\end{abstract}

Methods: After IRB approval, our patient database was retrospectively screened for patients who underwent a cerebral stent placement in which ticlopidine and aspirin was substituted for clopidogrel and aspirin. These patients were followed for signs and symptoms of cerebrovascular disease and complications of ticlopidine treatment.

Results: From 2009 to 2011, seven patients were identified to be clopidogrel resistant and no patients identified as allergic. Resistance was defined as less than $15 \%$ platelet inhibition on the VerifyNow ${ }^{\circledR}$ P2Y12 assay (Accumetrics Inc., San Diego, CA). Neither complications of cerebrovascular disease nor those associated with ticlopidine treatment were identified.

Conclusions: Ticlopidine and aspirin may be an appropriate treat-

Manuscript accepted for publication October 1, 2012

${ }^{a}$ Departments of Neurological Surgery, Center for Cerebrovascular and Endovascular Neurosurgery, Neurological Institute of New Jersey, University of Medicine and Dentistry of New Jersey, New Jersey Medical School, Newark, New Jersey, USA

${ }^{\mathrm{b}}$ Corresponding author: Charles J. Prestigiacomo, Department of Neurological Surgery, New Jersey Medical School, University of Medicine and Dentistry of New Jersey, 90 Bergen St, Suite 8100, Newark, NJ 07101 USA. Email: c.prestigiacomo@umdnj.edu

doi: http://dx.doi.org/10.4021/jnr142w ment alternative in patients who are resistant to clopidogrel and aspirin undergoing cerebral stenting.

Keywords: Dual antiplatelet therapy; Thienopyridine; Ticlopidine; Clopidogrel; Antiplatelet resistance; VerifyNow ${ }^{\circledR}$ P2Y12 assay; Cerebral stenting; Stent thrombosis; Stoke

\section{Introduction}

Recent technological advances in endovascular management of cerebrovascular disease have warranted the use of antiplatelet agents. Antiplatelet agents have had significant impact in reducing mortality and morbidity. Understanding the pharmacology and functionality of antiplatelet agents is tantamount to endovascular success. There is a growing body of literature that suggests that a percentage of the population is resistant or allergic to certain antiplatelet agents [1-5]. Consequently, providing an adequate substitute for this patient population is important to minimize adverse outcomes in stent therapy. We present a series of seven patients, who required stent placement but had contra-indications for the use of the standard antiplatelet regimen, aspirin and clopidogrel. Although there have been reports that discuss the use of ticlopidine with aspirin in the setting of intracranial stenting [6-9], there are no clear indications for its use. This paper discusses the indications of using ticlopidine with aspirin in the setting of intracranial stenting for patients who are not responsive to anti-platelet therapy with clopidogrel and aspirin. We report our findings for the use of ticlopidine as the agent of choice for patients that are refractory to clopidogrel.

\section{Methods}

Patients undergoing cerebral stenting in which ticlopidine replaced clopidogrel (both used with aspirin) in the setting of cerebral stenting were retrospectively identified as study subjects. Patients were classified as either clopidogrel resistant or allergic. Resistance was defined as less than $15 \%$ platelet inhibition on the VerifyNow ${ }^{\circledR}$ P2Y12 assay (Accu- 


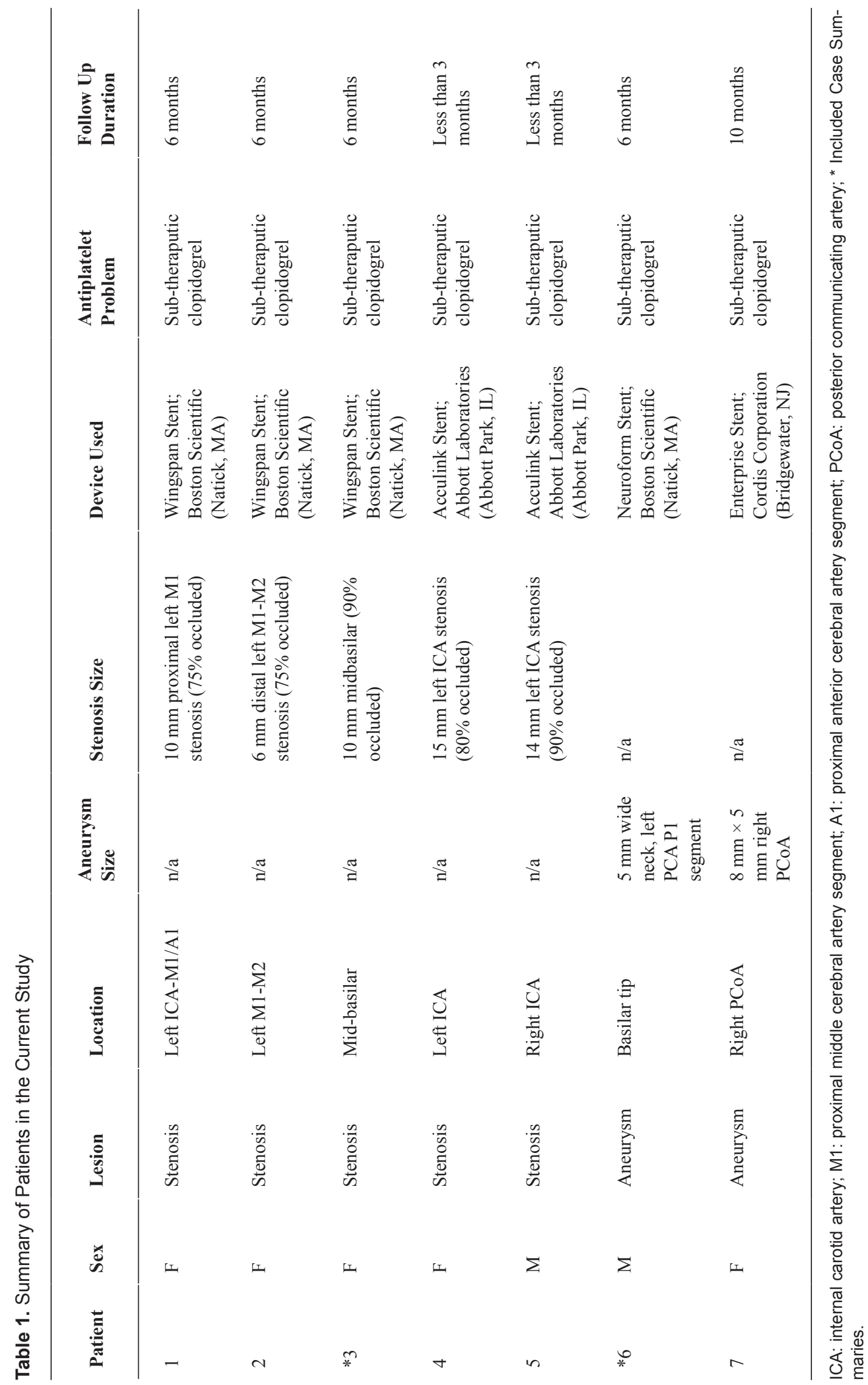




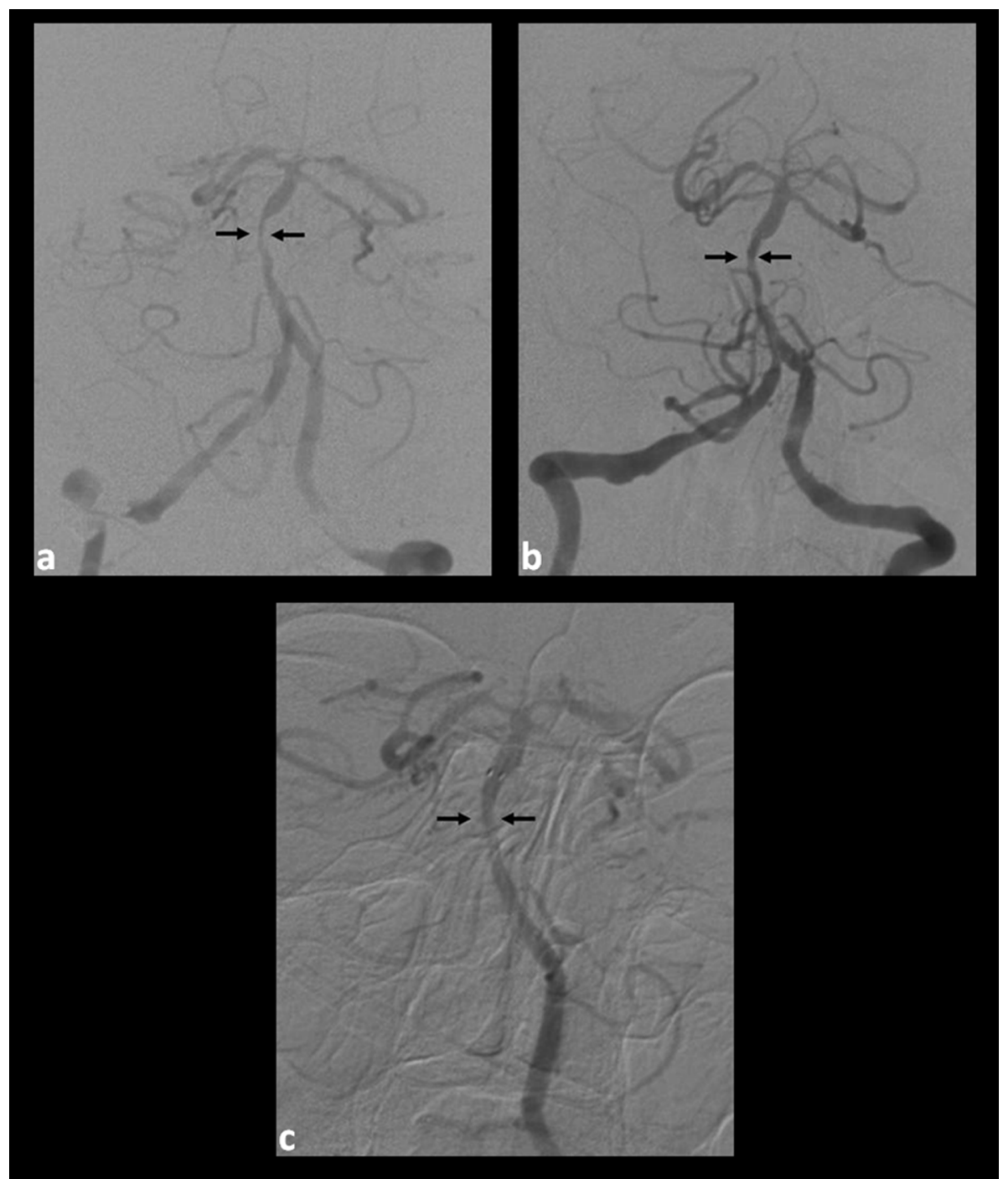

Figure 1. (a). Pre-intervention angiogram (cranial anteroposterior (AP) view) demonstrating stenosis of the mid-basilar artery; (b). Post-intervention angiogram (cranial AP view) demonstrating an increased caliber of the vessel after stent placement; (c). Six-month follow-up angiogram (cranial AP view) demonstrating significant remodeling and patency of the basilar artery at the level of the stent.

metrics Inc., San Diego, CA). They were subsequently monitored for signs and symptoms of cerebrovascular disease and complications associated with ticlopidine use using data assimilated from varied sources including clinical observation, laboratory studies and radiographic imaging.

\section{Results}

We identified 7 subjects ( 5 males, 2 females) with ticlopidine resistance as determined from the Plavix VerifyNow ${ }^{\circledR}$ assay used either prior or subsequent to endovascular treatment. No allergic patients were identified. Four of the 7 patients were identified as resistant pre-procedure and the remaining 3 were identified postoperatively. No signs and symptoms of ischemic disease or commonly reported complications of ticlopidine such as bleeding, neutropenia, thombocytic thrombocytopenia purpura were observed in these identified patients during the study period. Patients were followed up for a maximum of 10 months.

\section{Illustrative cases (Table 1)}

\section{Case 1, patient 3}

A 70-year-old woman with diabetes, hypertension, hyperlipidemia, coronary artery disease and myocardial infarction, presented with left facial droop, left-sided weakness and slurred speech. Home medications included atorvastatin 10 $\mathrm{mg}$ daily, aspirin $81 \mathrm{mg}$ daily and clopidogrel $75 \mathrm{mg}$ twice 
daily. Computed tomography (CT) head was unremarkable for infarction; however, magnetic resonance imaging (MRI) with diffusion weighted changes in the left upper pons and right mid-pontine regions were consistent with acute midbrain infarctions. A subsequent CT angiography (CTA) of the head and neck showed the mid-basilar artery with a severe stenotic segment, approximately $11 \mathrm{~mm}$ in length and diagnostic cerebral angiography confirmed a 75\% stenosis (Fig. 1a). Medications were adjusted: clopidogrel was continued at $75 \mathrm{mg}$ twice daily and the atorvastatin and aspirin were increased to $80 \mathrm{mg}$ and $325 \mathrm{mg}$ daily, respectively. Despite aggressive medical management, the patient began to exhibit multiple cranial nerve palsies confirmed by MRI evaluation to be secondary to expanding midbrain ischemia. A decision was made to place a stent across the basilar artery lesion.

The pre-operative Plavix Verify Now level was subtherapeutic and a $300 \mathrm{mg}$ loading dose was administered just prior to the procedure. Intra-operative heparin was administered to maintain the activated coagulation time (ACT) levels 1.5 to 2 times above baseline. Angioplasty with a Gateway $^{\mathrm{TM}}$ percutaneous transluminal angioplasty balloon was performed and subsequently a Wingspan ${ }^{\mathrm{TM}}$ (Boston Scientific, Natick, MA) stent was successfully placed. The aspirin $325 \mathrm{mg}$ daily and clopidogrel $75 \mathrm{mg}$ twice daily were continued post-operatively. Assessment of the clopidogrel-induced platelet inhibition remained sub-therapeutic despite increasing clopidogrel to $150 \mathrm{mg}$ three times daily. A decision was made to discontinue clopidogrel for resistance phenomenon and we initiated ticlopidine $250 \mathrm{mg}$ twice daily without a loading dose. Immediate follow-up angiograms showed improved basilar artery caliber (Fig. 1b). The patient was discharged to nursing home care with atorvastatin $80 \mathrm{mg}$ daily, aspirin $325 \mathrm{mg}$ daily and ticlopidine $250 \mathrm{mg}$ twice daily. A follow-up clinic evaluation revealed no signs and symptoms of disease or complaints of medication side effects and blood work was unremarkable. Diagnostic angiogram at 6 months showed remodeling of the basilar artery with satisfactory stent patency (Fig. 1c).

\section{Case 2, patient 6}

A 59-year-old man with hypertension, coronary artery disease, coronary stents and a known basilar artery apex nonruptured $5 \mathrm{~mm}$ wide-neck aneurysm, presented for elective stent-assisted coil embolization of the aneurysm. Pre-procedural anti-platelet medications were aspirin $325 \mathrm{mg}$ daily and clopidogrel $75 \mathrm{mg}$ daily. On the day of procedure, an Aspirin Verify Now level was therapeutic; however, Plavix VerifyNow ${ }^{\circledR}$ test showed $0 \%$ inhibition of the P2Y12 enzyme. The patient was given a $300 \mathrm{mg}$ loading dose of clopidogrel immediately prior to the procedure with intraoperative initiation of abciximab, a GP IIb/IIIa antagonist, that was discontinued 12 hours post-procedure. The aneu- rysm was successfully coiled with a Neuroform ${ }^{\mathrm{TM}}$ (Boston Scientific, Fremont, CA) stent placed across the neck and the patient was discharged home with aspirin $325 \mathrm{mg}$ daily and a doubled dose of clopidogrel $75 \mathrm{mg}$ twice daily. Plavix VerifyNow ${ }^{\circledR}$ was not repeated as abciximab interferes with test results. Patient was discharged with scheduled follow-up for repeat Plavix VerifyNow $®$.

One week post procedure, the patient presented with vertigo, left visual field disturbances, right upper arm tingling and unsteady gait. Physical examination showed decreased left rapid alternating movements, decreased pinprick of the left face, arm and leg, mild dysmetria of the left leg, and a positive Rhomberg sign. While head CT was unremarkable, MRI showed left greater than right cerebellar infarctions. CTA revealed stable stent placement without evidence of stent occlusion. The patient was challenged with clopidogrel $600 \mathrm{mg}$ twice daily for 24 hours followed by $150 \mathrm{mg}$ twice daily, but Plavix Verify Now results showed persistent subtherapeutic P2Y12 enzyme inhibition, consistent with clopidogrel resistance. Clopidogrel was discontinued and ticlopidine $250 \mathrm{mg}$ twice daily was initiated. The patient remained neurologically stable without symptom recurrence and was discharged to home. A follow-up clinic evaluation revealed no signs and symptoms of disease or complaints of medication side effects and blood work was unremarkable. Diagnostic angiogram at 6 months showed complete obliteration of the aneurysm and satisfactory stent patency.

\section{Discussion}

Dual antiplatelet therapy with aspirin and a thienopyridine is the gold standard used in the neuroendovascular setting of intra-arterial stent placement [10-12]. Evidence suggests that endothelial injury secondary to stent placement triggers an inflammatory response in the vessel wall. This vascular response is thrombogenic and may lead to thrombosis of the newly placed stent $[13,14]$. Aspirin and thienopyridines inhibit platelet aggregation via different pathways and thus exert a synergistic effect to prevent this thrombotic occlusion $[15,16]$. Clopidogrel is currently the thienopyridine of choice in dual therapy for stenting because of its reported superior tolerability and safety profile when compared to ticlopidine $[12,17]$. However, clopidogrel may not be a suitable antiplatelet therapy for some patients. Contraindications for clopidogrel include drug hypersensitivity and resistance to the desired therapeutic effect [4]. Resistance, or decreased responsiveness to clopidogrel, can be defined as the lack of the desired decrease in platelet activity in response to drug administration and may result in increased risk of thrombotic events [2]. Although allergic patients can be desensitized, this may be impractical in the clinical setting of acute cerebral vascular insult [3].

Alternative thienopyridines can be used in patients 
with clopidogrel hypersensitivity or poor responsiveness [18]. Ticlopidine is an equally effective antithrombotic [17, 19-22]. For example, the Canadian American Ticlopidine Study (CATS) established that in patients with recent stroke, ticlopidine monotherapy reduced the rate of subsequent stroke, myocardial infarct, or vascular death [23]. The cardiac stenting literature has demonstrated the combination therapy of ticlopidine with aspirin to be a safe and effective [24-27]. Numerous studies have shown that the combination is associated with lower rates of thrombotic-stent occlusion $[26,28,29]$. Use of ticlopidine in intracranial stenting has been described; however the neuroendovascular literature regarding the use of ticlopidine in the setting of patients with clopidogrel resistance is limited [6-9]. Our study demonstrates that ticlopidine plus aspirin is an effective alternative to clopidogrel plus aspirin for patients undergoing cerebral stenting. Though clopidogrel was the initial thienopyridine of choice for all patients in this study, nonresponsive patients were switched to ticlopidine. Anti-platelet therapy with ticlopidine and aspirin was found to be well tolerated by all patients at latest follow-up. Patients remained clinically asymptomatic and with no instances of bleeding, neutropenia, thrombotic thrombocytopenia purpura related to treatment.

Ticlopidine, like clopidogrel (and prasugrel), is a thienopyridine that inhibits ADP-mediated platelet aggregation resulting in increased bleeding time and delayed clot retraction. It is metabolized by the hepatic cytochrome P450 enzyme into an unidentified active compound before it can inhibit platelet aggregation.[30] Platelet inhibition is concentration and time dependent, with significant platelet inhibition occurring after 3 to 5 days of administration [31]. The anti-platelet activity may last up to 10 days after therapy is ceased, suggesting that it irreversibly blocks platelet aggregation [32]. Within the first four years after ticlopidine's release in 1991, 25 cases of thrombotic thrombocytopenic purpura were reported to the FDA [33]. Moreover, 2.4\% of treated patients had neutropenia of which $0.8 \%$ of reported cases were severe [34]. When clopidogrel was introduced to the market, it showed similar clinical efficacy and pharmacological activity, but had an improved safety profile [35]. TTP has been reported in only 11 patients since clopidogrel was introduced in 1997 [36]. Furthermore, only $0.05 \%$ of patients using clopidogrel experienced severe neutropenia $[5,37]$.

Although TTP and neutropenia are important complication, they are still relatively uncommon events amongst ticlopidine users. The incidence of TTP ranges from 1 in 1,600 to 1 in 5,000 patients. It occurs in the early weeks of therapy, from 2 to 8 weeks of initiation. By implementing rigorous monitoring of drug-related adverse events with bimonthly surveillance of blood counts for 3 months as we practice at our institution, the morbidity and mortality associated with ticlopidine is minimized. Additionally, early treatment of thienopyridine-induced TTP is effective and definitive, with most patients being relapse-free for life [38]. Thus, with improved secondary and tertiary prevention tactics, ticlopidine should be considered as an alternative to clopidogrel for patients undergoing cerebral stenting. Furthermore, there is significant variation amongst neurointerventionalists regarding duration of dual antiplatelet protocol when using intracranial stents for various indications, with some protocols reducing the use of thienopyridine to less than 3 months. This reduced treatment window for ticlopidine thus reduces its potential for side effects while still being efficacious.

Although the use of ticlopidine in the cardiovascular literature in coronary stenting has been extensively reported, only a few trials comparing the clinical efficacy and safety of ticlopidine versus clopidogrel exist. Mullet et al found to have comparable efficacy profiles after coronary stent placement; however the ticlopidine group was associated with a higher rate of non-cardiac complications, leukopenia or thrombocytopenia. Although not statistically significant, the clopidogrel group experienced a higher rate of thrombotic stent occlusion [39]. Moussa et al found both anti-platelet drugs to have a similar rate of in-stent thrombosis and major adverse cardiac events with no differences in the incidence of side effects including neutropenia. However, patients receiving ticlopidine were more likely to report at least one side effect [40]. Furthermore, although clopidogrel has a reported comparable cost to ticlopidine, some pharmacies have a substantial reduction in cost for ticlopidine probably due to the availability of a generic form [29, 41]. Large, multicentered randomized trials juxtaposing both thienopyridines in coronary and cerebral stenting is necessary to compare efficacy and safety profiles as well as cost effectiveness of each therapy.

A large variability in clopidogrel response is known to exist among patients; Snoep et al conducted a meta-analysis of 25 studies that revealed a mean prevalence of clopidogrel resistance to be $20 \%[1,5]$. Current school of thought for clopidogrel resistance includes increased reactivity of resting platelets with drug administration, dysfunction of cytochrome p450 due to genetics or drug cross reactions, variability in the ADP receptor, and/or patient differences in resorption [42]. There is less data regarding variability in patient response to ticlopidine. In 2007, Campo et al found a $19 \%$ prevalence of ticlopidine resistance amongst patients $[1,43,44]$. Interestingly, the rate of simultaneous resistance to ticlopidine and clopidogrel in patients needing cerebral stenting is not reported. However, based on a rate of crossresistance of $3.5 \%$ in the cardiovascular literature it seems reasonable to assume a similarly low rate in the cerebral setting [1]. These findings suggest that both drugs inhibit ADPmediated platelet aggregation via different pharmacological mechanisms, thus further establishing ticlopidine with aspirin as a suitable substitute for clopidogrel resistant patients.

Although they accurately measure clopidogrel response in vivo, clinical accuracy of platelet function assays is still 
unknown. Clopidogrel resistance can be measured by various techniques. Light transmitted aggregometry is considered to be the gold standard for measurement of clopidogrel effectiveness but is exclusive to a few laboratories because of its time consuming nature. Recently, easier and more accurate assays such as the VerifyNow ${ }^{\circledR}$ P2Y12 assay have become standard in many hospital settings, as in ours [4547]. This test prevents nonspecific activation of platelets and corrects for baseline platelet activity, making this test more specific for the inhibition from clopidogrel [48]. The VerifyNow ${ }^{\circledR}$ P2Y 12 correlates well with levels of clopidogrel in the plasma and has thus been reported as one of the most accurate assays of platelet activity in response to the drug [45]. Less than $15 \%$ inhibition or greater than 213 P2Y12 reactive units (PRU) represents clopidogrel resistance, a standard we have adopted in our institution [48]. Although similar methods for resistance measurements exist for aspirin therapy, no method currently exists to measure response to ticlopidine. Thus, it is difficult to follow the efficacy of ticlopidine as done with the other antiplatelet agents. Physicians must rely on the clinical evaluation to ensure that the adequate antiplatelet effect is delivered. Thus, ticlopidine should only be used in the setting of clopidogrel resistance (or allergy) as its efficacy can be monitored.

The use of platelet inhibition assays remains controversial. In fact, many centers do not use the assay for stenting. There is some evidence that therapy should not be modified on the basis of assay results, such as the VerifyNow ${ }^{\circledR}$, as they may not be predictive of clinical events [49]. The Popular study found that the prognostic accuracy of these tests, i.e. risk of post-operative bleeding, were only modest [46]. Lordkipandize et al reported an overestimation of platelet aggregation with the VerifyNow ${ }^{\circledR}$ assay in patients with coronary artery disease, which could lead to a flawed risk reduction calculation for ischemic events [47]. Interference with test results when patients are treated with abciximab has been reported [50]. This is important as we report some patients requiring immediate antiplatelet treatment pre or intra operatively. Although symptomatic patients require a change in therapy, asymptomatic patients with resistance phenomenon measured by the VerifyNow ${ }^{\circledR}$ assay may or may not benefit from, or may even be at risk for complications from switching regimens. The patients in this study exhibited no further progressive symptoms after instituting aspirin and ticlopidine .Thus, the judicious use of ticlopidine in the setting of clopidogrel resistance or allergy should be considered as a viable and safe alternative. However, using ticlopidine for asymptomatic patients in the setting of clopidogrel resistance must still be investigated, as no assay exists to monitor ticlopidine resistance.

\section{Conclusions}

The use of clopidogrel with aspirin in the neuroendovascular management of cerebrovascular disease has been associated with a significant reduction in morbidity and mortality. It is essential to establish an effective antiplatelet alternative for patients that are either allergic or resistant to clopidogrel. Our case series suggests that judicious use of ticlopidine with aspirin may be a safe, cost-effective, and viable alternative for antiplatelet therapy in this population. Indeed, this small retrospective analysis suggests that its initial benefits, when used in a limited time window, may outweigh its risks, especially in the setting clopidogrel resistance. Larger, multi-centered randomized trials are needed to validate ticlopidine for antiplatelet therapy in the neuroendovascular setting. The data from this small retrospective serious suggest that ticlopidine be re-evaluated as one of the antiplatelet agents of choice in the setting of a short-term regimen to prevent acute and delayed in-stent thrombosis.

\section{References}

1. Campo G, Valgimigli M, Gemmati D, Percoco G, Catozzi L, Frangione A, Federici F, et al. Poor responsiveness to clopidogrel: drug-specific or class-effect mechanism? Evidence from a clopidogrel-to-ticlopidine crossover study. J Am Coll Cardiol. 2007;50(12):11321137.

2. Muller-Schunk S, Linn J, Peters N, Spannagl M, Deisenberg M, Bruckmann H, Mayer TE. Monitoring of clopidogrel-related platelet inhibition: correlation of nonresponse with clinical outcome in supra-aortic stenting. AJNR Am J Neuroradiol. 2008;29(4):786-791.

3. Owen P, Garner J, Hergott L, Page RL, 2nd. Clopidogrel desensitization: case report and review of published protocols. Pharmacotherapy. 2008;28(2):259-270.

4. Simon DI, Jozic J. Drug-eluting stents and antiplatelet resistance. Am J Cardiol. 2008;102(9 Suppl):29J-37J.

5. Snoep JD, Hovens MM, Eikenboom JC, van der Bom JG, Huisman MV. Association of laboratory-defined aspirin resistance with a higher risk of recurrent cardiovascular events: a systematic review and meta-analysis. Arch Intern Med. 2007;167(15):1593-1599.

6. Lylyk P, Cohen JE, Ceratto R, Ferrario A, Miranda C. Angioplasty and stent placement in intracranial atherosclerotic stenoses and dissections. AJNR Am J Neuroradiol. 2002;23(3):430-436.

7. Lanzino G, Wakhloo AK, Fessler RD, Hartney ML, Guterman LR, Hopkins LN. Efficacy and current limitations of intravascular stents for intracranial internal carotid, vertebral, and basilar artery aneurysms. J Neurosurg. 1999;91(4):538-546.

8. Uchiyama N, Kida S, Watanabe T, Yamashita J, Matsui O. Improved cerebral perfusion and metabolism after stenting for basilar artery stenosis: technical case report. Neurosurgery. 2001;48(6):1386-1391; discussion 1391- 
1382.

9. Vanninen R, Manninen H, Ronkainen A. Broad-based intracranial aneurysms: thrombosis induced by stent placement. AJNR Am J Neuroradiol. 2003;24(2):263266.

10. Chaturvedi S, Yadav JS. The role of antiplatelet therapy in carotid stenting for ischemic stroke prevention. Stroke. 2006;37(6):1572-1577.

11. Mohammad RA, Goldberg T, Dorsch MP, Cheng JW. Antiplatelet therapy after placement of a drug-eluting stent: a review of efficacy and safety studies. Clin Ther. 2010;32(14):2265-2281.

12. Reaume KT, Regal RE, Dorsch MP. Indications for dual antiplatelet therapy with aspirin and clopidogrel: evidence-based recommendations for use. Ann Pharmacother. 2008;42(4):550-557.

13. Bennett MR. In-stent stenosis: pathology and implications for the development of drug eluting stents. Heart. 2003;89(2):218-224.

14. Mitra AK, Agrawal DK. In stent restenosis: bane of the stent era. J Clin Pathol. 2006;59(3):232-239.

15. Urban P, Macaya C, Rupprecht HJ, Kiemeneij F, Emanuelsson H, Fontanelli A, Pieper M, et al. Randomized evaluation of anticoagulation versus antiplatelet therapy after coronary stent implantation in high-risk patients: the multicenter aspirin and ticlopidine trial after intracoronary stenting (MATTIS). Circulation. 1998;98(20):2126-2132.

16. Bossavy JP, Thalamas C, Sagnard L, Barret A, Sakariassen K, Boneu B, Cadroy Y. A double-blind randomized comparison of combined aspirin and ticlopidine therapy versus aspirin or ticlopidine alone on experimental arterial thrombogenesis in humans. Blood. 1998;92(5):15181525.

17. Bertrand ME, Rupprecht HJ, Urban P, Gershlick AH. Double-blind study of the safety of clopidogrel with and without a loading dose in combination with aspirin compared with ticlopidine in combination with aspirin after coronary stenting : the clopidogrel aspirin stent international cooperative study (CLASSICS). Circulation. 2000;102(6):624-629.

18. Fileti L, Campo G, Valgimigli M, Marchesini J, Ferrari R. [Current options to manage clopidogrel poor responsiveness]. G Ital Cardiol (Rome). 2010;11(12):881-889.

19. Serruys PW, Kutryk MJ, Ong AT. Coronary-artery stents. N Engl J Med. 2006;354(5):483-495.

20. Bell B, Walters D, Spaulding C. Deciphering dual antiplatelet therapy in the era of drug-eluting coronary stents. Curr Drug Targets. 2009;10(6):519-529.

21. Guasch E, Sionis A, Reverter JC, Andrea R, Loma-Osorio P, Freixa X, Heras M. Safety issues of adjunctive clopidogrel in patients discharged after percutaneous coronary intervention with stent placement and requiring oral anticoagulation. Int J Cardiol. 2011;146(1):e1-
4.

22. Jarvis B, Simpson K. Clopidogrel: a review of its use in the prevention of atherothrombosis. Drugs. 2000;60(2):347-377.

23. Gent M, Blakely JA, Easton JD, Ellis DJ, Hachinski VC, Harbison JW, Panak E, et al. The Canadian American Ticlopidine Study (CATS) in thromboembolic stroke. Lancet. 1989;1(8649):1215-1220.

24. Bertrand ME, Legrand V, Boland J, Fleck E, Bonnier J, Emmanuelson H, Vrolix M, et al. Randomized multicenter comparison of conventional anticoagulation versus antiplatelet therapy in unplanned and elective coronary stenting. The full anticoagulation versus aspirin and ticlopidine (fantastic) study. Circulation. 1998;98(16):1597-1603.

25. Kastrati A, Schuhlen H, Hausleiter J, Walter H, Zitzmann-Roth E, Hadamitzky M, Elezi S, et al. Restenosis after coronary stent placement and randomization to a 4-week combined antiplatelet or anticoagulant therapy: six-month angiographic follow-up of the Intracoronary Stenting and Antithrombotic Regimen (ISAR) Trial. Circulation. 1997;96(2):462-467.

26. Leon MB, Baim DS, Popma JJ, Gordon PC, Cutlip DE, Ho KK, Giambartolomei A, et al. A clinical trial comparing three antithrombotic-drug regimens after coronaryartery stenting. Stent Anticoagulation Restenosis Study Investigators. N Engl J Med. 1998;339(23):1665-1671.

27. Schomig A, Neumann FJ, Kastrati A, Schuhlen H, Blasini $\mathrm{R}$, Hadamitzky $\mathrm{M}$, Walter $\mathrm{H}$, et al. A randomized comparison of antiplatelet and anticoagulant therapy after the placement of coronary-artery stents. N Engl J Med. 1996;334(17):1084-1089.

28. Goods CM, al-Shaibi KF, Liu MW, Yadav JS, Mathur A, Jain SP, Dean LS, et al. Comparison of aspirin alone versus aspirin plus ticlopidine after coronary artery stenting. Am J Cardiol. 1996;78(9):1042-1044.

29. Majid A, Delanty N, Kantor J. Antiplatelet agents for secondary prevention of ischemic stroke. Ann Pharmacother. 2001;35(10):1241-1247.

30. Tran H, Anand SS. Oral antiplatelet therapy in cerebrovascular disease, coronary artery disease, and peripheral arterial disease. JAMA. 2004;292(15):1867-1874.

31. Di Minno G, Cerbone AM, Mattioli PL, Turco S, Iovine C, Mancini M. Functionally thrombasthenic state in normal platelets following the administration of ticlopidine. J Clin Invest. 1985;75(2):328-338.

32. Uchiyama S, Sone R, Nagayama T, Shibagaki Y, Kobayashi I, Maruyama S, Kusakabe K. Combination therapy with low-dose aspirin and ticlopidine in cerebral ischemia. Stroke. 1989;20(12):1643-1647.

33. Wysowksi DK, Bacsanyi J. Blood dycrasias and hematologic reactions in ticlopidine users. JAMA. 1996;276(12):952.

34. Besson G, Bogousslavsky J. [European atrial fibrillation 
trial (EAFT). Secondary prevention with anticoagulants and aspirin in patients with non-valvular atrial fibrillation having suffered a transient ischemic attack or a regressive vascular accident]. Rev Med Suisse Romande. 1991;111(1):49-55.

35. Quinn MJ, Fitzgerald DJ. Ticlopidine and clopidogrel. Circulation. 1999;100(15):1667-1672.

36. Bennett CL, Kiss JE, Weinberg PD, Pinevich AJ, Green D, Kwaan HC, Feldman MD. Thrombotic thrombocytopenic purpura after stenting and ticlopidine. Lancet. 1998;352(9133):1036-1037.

37. Schror K. Antiplatelet drugs. A comparative review. Drugs. 1995;50(1):7-28.

38. Yagi H. [Clinical features and laboratory findings of thrombotic thrombocytopenic purpura associated with ticlopidine]. Rinsho Byori. 2005;53(7):630-638.

39. Muller C, Buttner HJ, Petersen J, Roskamm H. A randomized comparison of clopidogrel and aspirin versus ticlopidine and aspirin after the placement of coronaryartery stents. Circulation. 2000;101(6):590-593.

40. Moussa I, Oetgen M, Roubin G, Colombo A, Wang X, Iyer S, Maida R, et al. Effectiveness of clopidogrel and aspirin versus ticlopidine and aspirin in preventing stent thrombosis after coronary stent implantation. Circulation. 1999;99(18):2364-2366.

41. Sharis PJ, Cannon CP, Loscalzo J. The antiplatelet effects of ticlopidine and clopidogrel. Ann Intern Med. 1998;129(5):394-405.

42. Geiger J, Teichmann L, Grossmann R, Aktas B, Steigerwald U, Walter U, Schinzel R. Monitoring of clopidogrel action: comparison of methods. Clin Chem. 2005;51(6):957-965.

43. Fuchigami S, Oshima S, Hokimoto S, Noda K, Fukushima H, Yoshida T, Takushi Y, et al. Subacute thrombosis after coronary stenting occurring with resistance to ticlopidine. Intern Med. 2006;45(10):675-678

44. Obergfell A, Strotmann J, Bonz A, Bauersachs J, Ertl G, Walter U, Grossmann R. Impaired platelet responses to clopidogrel and ticlopidine in a patient with recurrent coronary stent stenosis. Thromb Haemost. 2004;92(6):1446-1447.

45. Bouman HJ, Parlak E, van Werkum JW, Breet NJ, ten Cate H, Hackeng CM, ten Berg JM, et al. Which platelet function test is suitable to monitor clopidogrel responsiveness? A pharmacokinetic analysis on the active metabolite of clopidogrel. J Thromb Haemost. 2010;8(3):482-488.

46. Breet NJ, van Werkum JW, Bouman HJ, Kelder JC, Ruven HJ, Bal ET, Deneer VH, et al. Comparison of platelet function tests in predicting clinical outcome in patients undergoing coronary stent implantation. JAMA. 2010;303(8):754-762.

47. Lordkipanidze M, Pharand C, Nguyen TA, Schampaert E, Diodati JG. Assessment of VerifyNow P2Y12 assay accuracy in evaluating clopidogrel-induced platelet inhibition. Ther Drug Monit. 2008;30(3):372-378.

48. Godino C, Mendolicchio L, Figini F, Latib A, Sharp AS, Cosgrave J, Calori G, et al. Comparison of VerifyNowP2Y12 test and Flow Cytometry for monitoring individual platelet response to clopidogrel. What is the cut-off value for identifying patients who are low responders to clopidogrel therapy? Thromb J. 2009;7:4.

49. Christiaens L, Macchi L. Monitoring of the antiplatelet drugs effect in patients with coronary artery disease: what is the real clinical impact? Curr Vasc Pharmacol. 2007;5(4):293-301.

50. Malinin A, Pokov A, Swaim L, Kotob M, Serebruany V. Validation of a VerifyNow-P2Y12 cartridge for monitoring platelet inhibition with clopidogrel. Methods Find Exp Clin Pharmacol. 2006;28(5):315-322. 